University of Nebraska - Lincoln

DigitalCommons@University of Nebraska - Lincoln

Faculty Publications: Department of Teaching, Department of Teaching, Learning and Teacher Learning and Teacher Education

Education

2008

\title{
A Multi-Year Program Developing an Explicit Reflective Pedagogy for Teaching Pre-service Teachers the Nature of Science by Ostention
}

Mike U. Smith

Lawrence C. Scharmann

Follow this and additional works at: https://digitalcommons.unl.edu/teachlearnfacpub

Part of the Curriculum and Instruction Commons, and the Teacher Education and Professional Development Commons

This Article is brought to you for free and open access by the Department of Teaching, Learning and Teacher Education at DigitalCommons@University of Nebraska - Lincoln. It has been accepted for inclusion in Faculty Publications: Department of Teaching, Learning and Teacher Education by an authorized administrator of DigitalCommons@University of Nebraska - Lincoln. 


\title{
A Multi-Year Program Developing an Explicit Reflective Pedagogy for Teaching Pre-service Teachers the Nature of Science by Ostention
}

\author{
Mike U. Smith ${ }^{1}$ and Lawrence Scharmann ${ }^{2}$
}

1 Mercer University, Macon, GA, USA

2 Kansas State University, Manhattan, KS, USA

\begin{abstract}
.
This investigation delineates a multi-year action research agenda designed to develop an instructional model for teaching the nature of science (NOS) to preservice science teachers. Our past research strongly supports the use of explicit reflective instructional methods, which includes Thomas Kuhn's notion of learning by ostention and treating science as a continuum (i.e., comparing fields of study to one another for relative placement as less to more scientific). Instruction based on conceptual change precepts, however, also exhibits promise. Thus, the investigators sought to ascertain the degree to which conceptual change took place among students $(n=15)$ participating in the NOS instructional model. Three case studies are presented to illustrate successful conceptual changes that took place as a result of the NOS instructional model. All three cases represent students who claim a very conservative Christian heritage and for whom evolution was not considered a legitimate scientific theory prior to participating in the NOS instructional model. All three case study individuals, along with their twelve classmates, placed evolution as most scientific when compared to intelligent design and a fictional field of study called "Umbrellaology."
\end{abstract}

Published in Science \& Education 17 (2008), pp 219-248.

DOI: $10.1007 /$ s11191-006-9009-y

Copyright (C) Springer 2006. Used by permission. 


\section{Introduction}

Identifying effective means for teaching the nature of science (NOS) has become a central focus for science education in recent years. Studies have shown that, among children, adults, science teachers, and even scientists, an understanding of the NOS is meager at best. For example, $70 \%$ of the American adult respondents to the 2001 National Science Board Survey of Public Attitudes Toward and Understanding of Science and Technology did not hold an adequate "understanding of the scientific process" (National Science Board 2002). Sixty percent of the American NSB respondents agreed that some people possess psychic powers or ESP. In a Gallup poll of Americans more than 30\% reported beliefs in telepathy, extraterrestrial visitation, clairvoyance, and haunted houses (Newport and Strausberg 2001). Belief in astrology and the paranormal is even higher among Europeans (European Commission 2001). Effective arguments have been made on economic, utilitarian, democratic, cultural, and even moral grounds supporting the claim that functioning in a modern society requires a minimal level of understanding of the NOS (Driver et al. 1996, p. 11; see also McComas et al. 1998). Ongoing arguments over questions involved in the place of "equal time" for intelligent design and evolution in the biology classroom, the health risks of consuming genetically modified fruits and vegetables, and the collection, study and use of embryonic stem cells highlight the importance of NOS understanding. Recognizing the validity of these arguments, recent national standards documents adopted in different countries have included NOS understanding as a central theme refocusing both classroom teachers and science education researchers on questions about how this goal can be accomplished.

Crucial considerations to be addressed before research can be designed to answer this question include: What NOS should be taught? Or Whose NOS? Which aspects should be included? Alters (1997) and others have demonstrated diversity in descriptions of the NOS among philosophers of science, but others have argued that there is a remarkable consensus about the NOS at the level appropriate to members of the general population (Smith et al. 1997). The national standards documents reflect this consensus, presenting some 14 similar or identical NOS concepts (McComas et al. 1998). These concepts (or subsets of them) must therefore be the focus of our instructional programs. 
Science educators have also argued that it is self-evident that science teachers who teach the NOS must have an adequate NOS understanding themselves. Even when NOS is not a direct goal of teaching, the structure of the instruction likely sends implicit messages about the NOS (e.g., teaching mountains of "facts" sends the message that science is unchanging, not tentative). Studies of both preservice and in-service teachers, however, have largely revealed woefully inadequate levels of NOS understanding (Abd-El-Khalick and Lederman 2000). Therefore, before NOS instruction can focus on science students, it must focus on science teachers themselves. This instruction must not only provide teachers with the pedagogical content knowledge needed to teach the NOS but also promote advancement in teacher understanding of the NOS.

Early attempts at NOS instruction met with limited success (Palmquist and Finley 1997; Lederman 1999; Abd-El-Khalick and Lederman 2000). These studies supported the anecdotal experience of classroom teachers, even in cases where the instructor has an informed understanding of the NOS, that student learning of the NOS is typically very difficult to achieve. Research has identified a host of naïve and improper conceptions of science held by individuals in various study populations.

\section{Naive Understandings of the NOS}

A large number of qualitative, quantitative, and mixed method studies have supported three central claims about NOS understanding among both students and pre-service and in-service teachers. First, most people have inadequate understandings of the NOS (for review, see McComas et al. 1998). Three useful rubrics for analyzing NOS understandings have been developed. Lederman and colleagues distinguish between "naive" and "informed" NOS understandings (Akerson et al. 2000). Carey and colleagues (Carey et al. 1989; Carey and Smith 1993; Smith et al. 2000) proposed a three-level categorization scheme: Level 1 epistemology (lowest) - experimental results are seen as answers themselves, not as evidence for or against a particular idea; Level 2 epistemology - the purpose of science is to test ideas, but tentativeness or social construction of science are not understood; Level 3 epistemology - consistent with modern views of the 
NOS. The National Science Board (1996) used a 4-level scheme: Level I (highest) - understand that science involves developing and testing theories; Level II - do not understand this purpose of science but do recognize that experiments require control groups; Level III - lack the higher levels of understanding but recognize that science is based on careful and rigorous comparisons with precise measurements; Level IV - lack the above understandings. (Only 2\% of the 1995 American respondents held the highest level of science understanding.) Our own position is that understandings of the NOS change incrementally such that individuals at any given point in time fall along a continuum from more naïve to more well informed (Smith and Scharmann 1999). This position is most consistent with that of Eugenie Scott (1999).

Second, alternative conceptions that are inconsistent with currently accepted understanding of the NOS are commonly held. Individuals often hold that scientific conclusions are "truth," that science can be used to answer all questions, that supported theories become laws, that science provides "absolute proof," etc. (For a concise summary of common naive conceptions, see McComas 1996). Based on these findings, Khishfe and Abd-El-Khalick (2002) have proposed that the question of how to effectively facilitate NOS learning should be couched in terms of conceptual change theory. (See also Abd-El-Khalick and Akerson 2004).

Third, understanding of the NOS is often incoherent and fragmented. Student understandings of the NOS are best understood as components of conceptual frameworks that are not well organized and integrated with each other and may actually conflict with each other or with the resident cognitive structure. An individual may, for example, hold an informed view of the tentativeness of science but concurrently hold naïve views of the kinds of questions science can and cannot be used to answer. Similarly, it has long been recognized that individuals may "play the game of science" well in the classroom while holding conflicting personal views of science. Furthermore, individuals may be completely unaware of their conflicting views or may rationalize that no conflict exists (Gilbert et al. 1982). Although these findings are not incompatible with calls for viewing NOS instruction as a conceptual change problem, conceptual change theorists typically view the individual's understanding of a concept as a less fragmented, more integrated whole. They generally consider the difficulty of any learning that requires discarding an alternative conception to 
be a function of how deeply integrated that misconception is within the individual's conceptual ecology (Hewson et al. 1998).

Others have argued that it may be fruitful to view the problem of NOS learning as one of cultural "border crossing" (Aikenhead and Jegede 1999). In this view many students experience science as a "culture" that is not only distinct from their out-of-school culture but may also be so "discordant" with their personal worldviews that adopting a scientific view of the world (or view of science itself at least) feels "hazardous," jeopardizes the student's self-esteem, threatens his ego, and may cause "psychological pain." Aikenhead and Jegede described, for example, a student whose personal faith was so "heavily influenced by his fire and brimstone home microculture" that crossing the border into school science was impossible (p. 281). The emotional and psychological risk was simply too great. We are familiar with such students for whom considering the possibility that science may not of necessity conflict with religion threatens their foundational image of themselves as believers.

According to Aikenhead and Jegede (1999), science instruction that accounts for such students must encourage "flexibility and feeling at ease." "Flexibility can best be achieved by an attitude ... Lugones (1987) described as "playful" (p. 273). We think of flexibility/playfulness as the ability to "try it on, to see how it feels," to see if this view might make sense without making a personal investment of any kind in the new view and not rejecting any personally held commitments. This is, for example, the ability required of a student who is asked to argue for a position he does not hold in an effort to enhance that student's understanding of that position. This concept goes hand in hand with that of "feeling at ease." "Ease is conceived as a cluster of factors: (a) being a fluent speaker, (b) agreeing with the norms of that culture, (c) being humanly bonded with people in that culture, and (d) having a sense of shared history" (p. 273). Indeed, a substantial number of our students have grave difficulty using scientific terms appropriately, patently disavow the norms of scientists (or have at least been encouraged by their ministers to do so), have never known a scientist, and have no sense of shared history with scientists. For at least some students, then, the issue may not be limited to the fact that understanding the philosophy underlying the NOS is so cognitively challenging or that they harbor tenaciously held alternative conceptions. From this view, these students also enter our classrooms ill at ease and fearing that their basic precepts will be challenged. 


\section{NOS Instruction}

Taking into consideration these findings about student understanding of the NOS, several different approaches for teaching the NOS have been developed. (For reviews, see Lederman 1992; Lederman and Abd-El-Khalick 1998; Abd-El-Khalick and Lederman 2000; Khishfe and Abd-El-Khalick 2002). McComas et al. (1998) identify four approaches to NOS instruction based on where the instruction is situated: within methods courses, within science content classes, within authentic science experiences (e.g., internships in research laboratories), and within self-contained NOS courses or units. In large part, we hold most claims for any one of these approaches and against the others to be straw-man arguments. We share the view of McComas et al. (1998) and others that NOS understanding may best be enhanced when students learn informed views of the NOS, not just in one class, but when they encounter mutually consistent views of the NOS across more than one setting.

Alternatively, Abd-El-Khalick and Lederman (2000) distinguish between implicit and explicit approaches to NOS instruction: Implicit NOS instruction assumes that students can learn the NOS by "doing science." Students engage in science-based activities, but NOS issues are not specifically addressed. In contrast, explicit NOS instruction takes NOS learning to be a direct target, not a side effect of the learning experience. Aspects of the NOS are directly addressed with students. In keeping with a constructivist view of learning, explicit instruction has typically included extensive opportunities for students to reflect on their understandings of the NOS and how the readings, lectures, or other learning activities impact those understandings. According to Abd-El-Khalick and Lederman (2000), the difference between the two types of instruction

lies in the extent to which learners are provided (or helped to come to grips) with the conceptual tools, such as some key aspects of NOS, that would enable them to think about and reflect on the activities in which they are encouraged (p. 690).

Although there has been no research to date directly comparing the two modes of NOS instruction in a single study, the weight of the 
available evidence from numerous studies of programs that employed one or the other clearly favors explicit reflective NOS instruction over the relatively ineffective implicit mode for developing NOS understanding (Abd-El-Khalick and Lederman 2000).

Research studies have employed a wide variety of materials and methods for use in explicit reflective NOS instruction, including reflective journal writing, small and/or large group lectures and discussions, teacher questioning, science-embedded activities, card sorts/ card exchange games using NOS concepts, concept mapping, analysis of critical and typical teaching incidents, presentations by visiting expert speakers (scientists, philosophers, historians of science, classroom teachers who teach NOS, etc.), debates, readings, videos, developing lesson plans that address both science content and NOS, historical case studies, and comparing positions of philosophers, historians, and sociologists of science. (An excellent guide to the use of many of these materials is available. See McComas 1996.)

The primary question arising from this literature, of course, is: How effective have these attempts been at promoting an informed understanding of the NOS among students? After an extensive review of the literature, Abd-El-Khalick and Lederman (2000) concluded that instruction as reported in these studies has been largely unsuccessful. Gains in the experimental groups, when statistically significant, were often so small as to be of little practical significance. Also, because pretreatment understandings were so low, the relatively small gains obtained represent NOS understandings that are still unsatisfactorily limited.

A promising approach is the recent work of Abd-El-Khalick, Lederman and colleagues (Akerson et al. 2000; Abd-El-Khalick and Akerson 2004) who have studied the effects of an explicit reflective NOS instructional program for pre-service elementary teachers that is also based on the Hewson et al. (1998) guidelines for promoting conceptual change. Although this work has not included control groups, mean gain scores in the range of 24-68\% and absolute post-instructional mean scores of $69-82 \%$ (on various NOS aspects) are clearly of practical significance.

In summary, research to date strongly supports the use of explicit reflective instructional methods for NOS instruction but the practical success of instructional programs has been minimal. Instruction based on conceptual change precepts shows promise, but there still appears to be a need for effective approaches to NOS instruction, for which it 
may be valuable to seek guidance from other sources. We have found the following work to be particularly instructive.

\section{Teaching and Learning by Ostention}

\subsection{Kuhn and Ostention}

In The Structure of Scientific Revolutions, Kuhn (1962) argued that the history of science is best characterized as periods of "normal science" interrupted by periods of "revolutionary science" when old "paradigms" are replaced by new ones. According to Kuhn, scientists come to understand and share these paradigms by ostention. Defining a concept by ostention simply means clarifying "the meaning of the term by pointing to examples of things to which it applies" (Bonevac 1999). Thus, Kuhn would maintain that scientists recognize a new research question as acceptable by comparison with paradigmatic examples of related acceptable questions. (For a review of Kuhn's views on ostention, see Andersen 2000).

Kuhn argued that ostention is the primary mechanism by which children learn the concept labels for natural families of objects in everyday life. Kuhn's primary example was a child learning to distinguish ducks, geese, and swans (Kuhn 1974). Kuhn described a hypothetical situation in which Johnny learns to identify these waterfowl during a walk in a zoological garden with his father. Essentially, Johnny's father points out examples of each type of bird and Johnny attempts to identify each new bird they encounter. Sometimes he is right, sometimes he is wrong. "After a few more such encounters, however, each with its appropriate correction or reinforcement, Johnny's ability to identify these waterfowl is as great as his father's" (Kuhn 1974, p. 309). Understandings of categories such as "duck," "goose," and "swan" are therefore "transmitted from one generation to the next solely by extracting similarity relations from the exemplars on exhibit" (Andersen 2000). Kuhn's point is that children typically learn concept labels by exposure to examples in each category, not by learning lists of concept characteristics. "Anyone who has taught a child under such circumstances knows that the primary pedagogic tool is ostention. Phrases like 'all swans are white' may play a role, but they need not” (Kuhn 1974, p. 309). 
Philosophers may recognize that Kuhn's ideas about learning concepts that are difficult to explicitly define are based on Wittgenstein's analysis of the concept "games." (Think for example about a definition that would include solitaire, chess, and the children's game of "duck, duck, goose.”) Kuhn argued that, in practice, people come to understand the term "games" by ostention, by experience with examples and counterexamples of the term. He maintained that "the end product of the interaction between examples is nothing like a definition, a list of characteristics shared by games and only games, or of the features common" (Kuhn 1979, p. 413). In other words, there is no list of necessary and sufficient conditions to delineate unequivocally things that are games from things that are not. Based on this analysis, we argue that, although philosophers and science educators may find it fruitful to argue over feature lists of scientific characteristics, teaching the nature of science using such lists is likely to be less effective than beginning the instruction with prototypical examples.

\subsection{Contrasting Cases as Scaffolding for Learning}

The value of using contrasting cases to enhance learning (specifically to prepare students with limited prior knowledge for learning from lectures or expository texts) has received strong empirical support in a set of studies conducted at the Learning Technology Center at Vanderbilt University. In those studies, Schwartz and Bransford (1998) demonstrated that "generating the distinctions between contrasting cases" before reading or listening in lectures resulted in greater understanding (as evidenced by performance on subsequent prediction tasks) compared to control treatments. Schwartz and Bransford argue that "analyzing contrasting cases increased students' abilities to discern specific features that differentiated classes of ... phenomena" (p. 475). Furthermore, they argue that students engaged in this learning activity developed "the differentiated knowledge structures necessary to understand a subsequent explanation at a deep level" ( $p$. 504). "One may think of these contrasting cases," these researchers continue, "as a way to guide the students' discovery of significant features." Contrasting cases, therefore, provide scaffolding for the learning that is to follow. 


\subsection{Learning Science and Scientific Concepts by Ostention}

Kuhn extended his arguments about the value of ostention in learning to the learning of scientific concepts as well: "If, for example, the student of Newtonian dynamics ever discovers the meaning of terms like "force," "mass," "space," and "time," he does so less from the incomplete though sometimes helpful definitions in his text than by observing and participating in the application of these concepts to [a] problem solution" (Kuhn 1970, p. 47). "Students of physics regularly report that they have read through a chapter of their text, understood it perfectly, but nonetheless had difficulty solving the problems ... [As the student struggles with the problems, however, he/she] discovers a way to see his problem as like a problem he has already encountered" (Kuhn 1974, p. 305). Research in problem solving has, in fact, clearly demonstrated that learning to recognize the "deep-structure" similarities among problems is central to the understanding required for successful problem-solving performance. For example, experts are much more likely to recognize that a given pair of problems are "Newton's second law" problems, not "inclined plane" or "moving train" problems. Kuhn argues, however, that "it is after the similarity has been seen that one may ask for criteria, and it is then often worth doing so" (Kuhn 1974, p. 308, emphasis added).

Continuing his analysis of teaching the categorization of ducks, geese, and swans and of Wittgenstein's "games," Kuhn further argued that "most kind-terms [concept labels] must be learned as members of one or another contrast set" (Kuhn 1993, p. 371). In science, for example, learning the meaning of the term "liquid" requires learning the meaning of the terms "solid" and "gas" as well because whenever one places a particular example in one category, one is also of necessity not placing it in another. Kuhn continues, "Establishing the referent of a natural-kind [concept] requires exposure not only to varied members of that kind but also to members of others - to individuals, that is, to which the term might otherwise have been mistakenly applied" (Kuhn 1979, p. 413). Kuhn's example of the child learning to distinguish ducks, geese, and swans is meant as an example of learning to distinguish such a set of categories that might easily be confused.

Reflect for a moment on your own first understanding of the definition of the word "science". For most of us, it is probably impossible 
to remember when we first (if ever) learned an explicit definition. Instead, we are introduced to science by example - we take some "science" classes and others that are in "non-science" departments. Few if any of those classes ever define "science" explicitly. Initially, we learn what science is mostly by ostention. Often it is only scholars who become interested in the philosophy of science or in teaching the NOS who begin to think, read, and write about lists of the characteristics of science. Therefore "science" itself appears to be an example of a term that many science educators and presumably most scientists have come to understand initially by reference to examples.

It is important to point out, however, that Kuhn did not argue that all science learning (including NOS) should be exclusively by ostention - that there is no role for learning sets of accepted descriptors. Kuhn (1993) suggested that learning by ostention is most effective for the learning of natural families, i.e., contrasting sets between which there are clear discontinuities. The line of demarcation between science and non-science has, of course, been an exceedingly difficult one for both philosophers and students to draw. Thus, we may expect that instruction that employs ostention may be a valuable adjunct to NOS instruction but is unlikely to provide a single direct avenue toward the goal of effective NOS teaching and learning.

\subsection{Ostention and Categorization Research}

Psychological research supports Kuhn's perceptions (see Smith and Medlin 1981 for review). The body of categorization research strongly supports two general conclusions. First,

rather than representing concepts by sets of defining criteria, humans represent both natural and artificial concepts by a prototypical example. Category membership is determined by similarity or dissimilarity to the features of the prototype (Nersessian 1998, p. 96).

Second, "Subjects overwhelmingly agree in their judgments of how good an example or clear case members are of a category, even for categories about whose boundaries they disagree" (Rosch 1978, p. 36). Thus, although there may be substantial disagreement over whether 
creationism is or is not within the boundaries of science, there is likely wide agreement about the prototypes of science. One would assume, for example, that both creationists and evolutionists would tend to agree that physics (the "queen of the sciences") is a prototypical science. A side benefit of teaching that focuses on prototypical examples and counterexamples, therefore, may be that such instruction may help to avoid arguments about which list of NOS characteristics should be taught.

\subsection{Learning by Ostention and Concept Attainment}

The Kuhnian revolution and the cognitive revolution began at approximately the same time. There are notable connections among the problems with which each revolution was grappling, and with hindsight one can construct significant parallels between the views of knowledge, perception, and learning developed in each. However, by and large Thomas Kuhn never utilized research in the cognitive sciences that would have furthered his own paradigm in ways ... he would have found agreeable. (Nersessian 1998, p. 87)

Although Kuhn may not have been in a position to make direct use of insights from the cognitive sciences, we are not so constrained. In their classic text Models of Teaching Joyce et al. (2004) delineate adaptations of cognitive science research to teaching models. One such model, concept attainment, is adapted from the work of Jerome Bruner (Bruner et al. 1967). Concept attainment involves in part a "search for and listing of attributes that can be used to distinguish exemplars from nonexemplars" (Bruner et al. 1967, p. 233), and we acknowledge that this approach shares some features with Kuhnian ostention. Neither strategy, however, has previously been applied to NOS instruction.

In summary, we conclude that humans often tend to learn difficult-to define concepts by ostention, that it may be fruitful to apply Kuhn's ideas about ostention learning to learning about the NOS, and that ostention approaches may not be appropriate as the sole pedagogical avenue for NOS instruction. 


\section{A Proposed Instructional Approach to Teaching NOS by Ostention}

In recent years we have been engaged in the development of a pro-

gram for NOS instruction based on the following assumptions and claims drawn from the literature reviewed above:

1. NOS instruction at the secondary and undergraduate levels (outside of history and philosophy of science classes) should focus on those aspects of the NOS commonly agreed upon in the science education community (as set forth in the national standards documents).

2. Pre-service (and in-service) science teaching methods courses should promote NOS understanding. We take it as a given that if science teachers are to present effective NOS instruction, they must have both informed understandings of the NOS themselves and pedagogical content knowledge about effective NOS instruction.

3. NOS instruction is most likely to be effective if NOS concepts are addressed explicitly, not implicitly.

4. NOS instruction is most likely to be effective when it requires active cognitive engagement with NOS issues and requiring that students reflect on current positions as well as changes in their understandings.

5. NOS instruction is most likely to be effective if it employs conceptual change methodology, identifying common naïve conceptions held by the students; addressing these misconceptions directly; confronting situations in which present personal understandings are inadequate; discussing the intelligibility, plausibility, and fruitfulness of currently held and newly considered views of the NOS; and requiring justifications for judgments made (Hewson et al. 1998).

6. NOS instruction is most likely to be effective if it promotes integration of individual NOS concepts with each other as well as integration with in-school and out-of-school understandings of science-related issues.

7. The effectiveness of NOS instruction may be enhanced by promoting learning by ostention, focusing first on prototypical examples and counterexamples, employing contrasting sets of these 
examples, and sequencing these examples from most prototypical to borderline cases.

8. The effectiveness of NOS instruction is likely to be enhanced if students are asked to generate from these examples abstractions that can be used to compare science with non-science, as opposed to first presenting students with lectures and/or readings in which these abstractions are provided.

9. The effectiveness of NOS instruction is likely to be enhanced if every effort is made to ease the border crossing between the culture of school science and students' everyday world, by focusing on flexibility/playfulness and putting students at ease.

10. NOS instruction should use instructional models such as the learning cycle that have been shown to be effective in a broad range of other science content settings.

In the following sections we will briefly describe early iterations of the course, followed by a more detailed description of the structure of the current course that explains how the ten tenets have been employed as a foundation for our NOS instruction over the past five years. This section closes with the presentation of three case studies that provide insight into the effects of the course.

\section{Development of an Instructional Protocol: Implementations 1-3}

The course that provides the context for this work is entitled "Laboratory Techniques in the Teaching of Science" taught by the second author at a major research university in the American Midwest. Twelve hours of instruction are devoted to the NOS, which is one of the four major themes of the course. Students in the course include both graduate and undergraduate pre-service science teachers. Class size during the five years has ranged from 4 to 15 . Given the pervasiveness of conservative religious commitment among the students, many of the students came to the class with grave concerns about teaching evolution as well as about how their personal beliefs might be handled in this methods class. Additional details about the subjects and the course has been provided elsewhere (Scharmann et al. 2005).

The initial instructional unit was pilot tested and was then repeatedly revised based on available data sources and retested with 
students in implementation Years 2 and 3. The NOS component of the course was based on 9 of the 10 tenets listed above (all but \# 7 ostention), focusing on activities that required students to deal explicitly and reflectively with NOS concepts. (Application of each of the 10 tenets to the course design will be described in the following section.).

As expected, and as the course was designed for, the majority of students in these courses gave evidence of experiencing disequilibrium/cognitive dissonance between their own naïve views of the nature of science and more informed consensus views. Given the ongoing political furor over the science standards of the state in which the course is taught, much of the discussion focused on the scientific status of evolution and intelligent design. Interviews, electronic email exchanges with the course instructor, and regularly assigned response papers gave ample evidence that early iterations of the course facilitated more informed views of the NOS, even among some students who claimed to adhere to conservative Christian theology. In addition, results from these early iterations of the course supported the following conclusions:

- An understanding of the NOS is enhanced when NOS concepts are introduced in an explicit-reflective manner.

- Any instructional unit designed to introduce NOS concepts must be carefully sequenced.

- Science-religious issues need to surface immediately and be respectfully discussed throughout the duration of the instructional unit.

- When a NOS unit is structured in this manner, students who demonstrate strong religious belief (and anti-evolutionary sentiments) at the beginning of the course are less likely to feel threatened and more likely to be willing to "cross the border" and at least consider views that they previously found to be threatening. (A complete description of this iterative, action research agenda was published earlier. See Scharmann et al. 2005.)

\section{Current Course Structure: Implementations 4-5}

Beginning with the 2004 course, we sought to further enhance the course by directly integrating the previously described work on 
learning by ostention. As with earlier versions, the revised NOS unit was organized as an extended " 5 -E" learning cycle inquiry unit-plan (Dougherty 1997) (Tenet \#10). Instruction focused explicitly on enhancing student understanding of the NOS (Tenets \#2 and \#3) and required active cognitive engagement with NOS issues (Tenet \#4). Learning activities required students to generate criteria that can be used to evaluate the scientific status of a statement (Tenet \#8), and readings and instructor guidance during class discussions and electronic mail exchanges focused student thinking on aspects of consensus informed views of the NOS (Tenet \#1). The NOS unit provided multiple opportunities for reflection and justifications for judgments of intelligibility, plausibility, and fruitfulness (Tenet \#5) and provided subsequent opportunities to apply NOS concepts to judgments about concepts and issues relevant to both in-school and out-of-school settings (Tenet \#6). Every effort was made by the instructor, both implicitly and explicitly, to respect the religious views of the students and to establish an atmosphere in which students did not feel threatened - where they were encouraged to feel at ease and where they could make low-risk attempts to understand various claims (Tenet \#9). Activities involving learning by ostention were included throughout the course as described below. Features of the most recent iteration of the NOS instructional unit (enrollment 15) included the following: Engagement (10 minutes). Three activities were designed to promote learning NOS concepts by ostention (Tenet \#7). The first ostention activity was employed as part of the "engagement" phase of the learning cycle (see Figure 1). In this activity students were asked to individually consider pairs of terms and to determine which member of each pair was the "more scientific." This first set of item pairs was constructed to present the most prototypical examples of science and non-science so that the "more scientific" choice could be easily identified. Students unanimously chose the member of each pair consistent with informed views of the NOS with one exception. The pair that proved to be the most difficult choice was that of "Ecology - Management" (with Management being selected as more scientific by 5 of the 15 students). Through class discussion students related that they were unsure whether the term "management" was being used here to refer to business or to refer to science-related fields such as wildlife or range management. This result was unexpected but gave evidence that the activity had achieved our purposes of promoting active 
Figure 1. NOS Task 1.

1.Consider each of the following paired terms and circle the one you would consider to be the "more scientific."

Drama--Physics

Mechanics--Literature

Music--Chemistry

Biology--Religion

Ecology--Management

History--Geology

2.Which pair(s) caused you the most difficulty?

cognitive engagement with NOS concepts (Tenet \#4) and demonstrating the commonality of views about the scientific status of these examples (part of Tenet \#7). The difficulty students had with the "ecology - management" pair also had the positive effect of demonstrating to students that it can be difficult to categorize a term or concept as scientific or non-scientific when the term is used out of context.

\subsection{Exploration (30 Minutes)}

In the second student task, somewhat less prototypical pairs of terms/concepts were presented - cases in which determining the relative scientific status of each term might be more controversial (e.g., astrology - astronomy; see Figure 2.) In order to introduce the concept of a continuum between science and non-science, in four cases a single term was paired with two others, one of which it was likely to be judged as more scientific and the other, less scientific. In our view, introducing students to the view that some ideas are more scientific than others is a primary instructional tool "easing border crossings," putting students at ease and showing the possibility of flexibility and respectful well-reasoned disagreement between individuals, even including students and the instructor (Tenet \#9). This nonconfrontational atmosphere was further promoted in this second student activity by the purposeful inclusion of pairs of terms (e.g., intelligent design - reincarnation) in which one member of the pair is a term whose legitimacy some students are likely to have a personal investment in is contrasted with a term that can appropriately be categorized as less scientific. Students find the inclusion of such pairs both surprising and liberating. 
Figure 2. NOS Task 2.

1.Individually, consider each of the following paired terms. Circle the term that appears to be the "more scientific" of the two. (Note: where a term is repeated you should consider it only with the term with which it is independently paired).

$$
\begin{gathered}
\text { Optics - Music } \\
\text { Reflexology - Acupuncture } \\
\text { Sociology - Advertising } \\
\text { Neurology -Acupuncture } \\
\text { Political Science - Psychology } \\
\text { Engineering - Military Science } \\
\text { Genetics - Computer Science } \\
\text { Engineering - Astrophysics } \\
\text { Channeling - Iridology } \\
\text { Theology - Education } \\
\text { Intelligent Design - Reincarnation } \\
\text { Biochemistry - Education } \\
\text { Astrology - Astronomy } \\
\text { Philosophy - Palmistry } \\
\text { Philosophy - Economics }
\end{gathered}
$$

2.Now examine your list with your partner(s). Develop a consensus list.

3. List below those criteria that you used to make your decisions.

Individuals again categorized the members of each pair as "more scientific" and or "less scientific." Students then selected a partner and attempted to achieve a consensus categorization for each pair of terms. Our purpose here was not only was to illustrate how science is socially constructed (consistent with a constructivist instructional model - Tenet \#4) but also to also provide opportunities for reflection and require students to justify their judgments on grounds of intelligibility, plausibility, and fruitfulness (Tenet \#5) - just as scientists develop criteria to assist in determining what counts as evidence or as individuals (outside of school) must make reasoned judgments about the relative scientific merits of various claims.

\subsection{Explanation (80 Minutes)}

Next the instructor (second author) guided students in whole-class discussion to come to a social consensus on NOS criteria used by all student teams as a basis for judging terms in the activities as more or less scientific. Criteria constructed by the students included the 
following: More scientific fields of study make claims that are testable (can be subjected to "if $\rightarrow$ then" reasoning), repeatable/verifiable, observable, measurable (quantifiable), and can lead to the development and testing of models. Students were then asked to test the validity of their socially constructed criteria on a third task in which pairs of students examined pairs of statements to determine which of the two statements (i.e., knowledge claims) was more reflective of science. Students were explicitly instructed to make these judgments based on their newly developed criteria (see Figure 3). Student pairs made their judgments and reported their decisions to the group. All student teams made judgments consistent with informed NOS views and gained experience applying consensus criteria for making these judgments.

The instructor then led students through an introduction to the $\mathrm{Na}$ tional Science Education Standards (National Research Council 1996) with specific reference to Content Standard G ("History and Nature of Science," pp. 200-204) which describes (a) science as a human endeavor, (b) nature of scientific knowledge, and (c) historical perspectives. Finally, students were asked to complete a nature of science quiz (Chiappetta and Koballa 2004) comprised of twelve T/F items based on statements from the National Science Education Standards. Student responses at this point in the course ranged from as few as four items to as many as nine items correct $(33-75 \%$; mean $=50 \%)$.

\subsection{Elaboration (6 Hours)}

Prior to each of the next three class sessions, students were asked to read two articles that focused explicitly on the NOS (Evening 1 Smith and Scharmann 1999; Clough and Olson 2004; Evening 2 - Niaz 2001; Scharmann and Smith 2001; Evening 3 - Somerville 1941; Peterson 2002). Students were requested to submit individual reflective essays for each of the readings, comparing the views of the authors both with the criteria developed in class and with those tenets listed in Content Standard G of the National Science Education Standards (National Research Council 1996). The instructor provided written iterative feedback to individual students between sessions. In addition, the instructor led class discussions based on critical issues raised by students in their reflective essays and also provided three inquiry activities (Black Boxes, "Humdingers," and Uncalibrated Thermometers) as detailed in our previous manuscript (Scharmann et al. 2005). 
Figure 3. NOS Task 3.

1. With your partner(s), read each pair of statements below.

2. For each pair of statements, identify one statement that is MORE reflective of science and one that is LESS reflective of science.

3. Justification: Explain how you made your decision for each pair. What is/are the main characteristic(s)/criteria that distinguish(es) the two members of each pair?

A. If you break a mirror, you will have seven years of bad luck

B. If hair color is inherited, then identical twin should have the same hair color.

C. Humans have a soul.

D. The rate of acceleration of all falling objects on earth is constant.

E. The rate of acceleration of an object due to the influence of the earth's gravity is 9.8 meters per second per second.

F. If you dream of tea, someone will die. This actually happened to me once.

G. Scientists in the 18th century believed that acquired traits (like musical performance ability) were inherited. Research data later showed this to be largely false.

$\mathrm{H}$. Some people believe that the earth is flat because it looks flat to them. They are not willing to consider other data such as pictures of the earth taken from space.

I. If HIV causes AIDS, then every person with AIDS should have the virus in their body.

J. Humans today are the reincarnations of people in the past.

$\mathrm{K}$. Astrology is the prediction of the future from the stars. Astrology has not led to new hypotheses and other areas of study.

L. Genetics is a fertile new science that has led to many new hypotheses and new area of study.

M. Some people believe that placing magnets on parts of the body that hurt will cure the problem. They are unwilling to consider the possibility that they could be wrong.

N. Experiments in psychology are often replicated because psychologists recognize that the conclusions of earlier experiments could be wrong.

O. In 1989, researchers reported that they had been able to perform cold fusion -- a process widely thought by others to be impossible. Many people did not believe the researchers until they saw the data themselves.

P. A parapsychologist "reads the mind" of another person. The audience is awed by the parapsychologist's skill.

Q. If the Koran says it is so, it is so.

R. Many scientists do not believe that Vitamin C will prevent the common cold even though Linus Pauling, the Nobel laureate who discovered the structure of Vitamin C, claimed it will.

S. I believe that God loves me

T. The average IQ in the freshman class is over 100. 


\subsection{Evaluation (4 Hours)}

Three culminating activities were provided and the NOS quiz (Chiappetta and Koballa 2004) was re-administered to represent the "evaluation" phase of the unit-plan learning cycle. The first two activities were performance based.

\subsubsection{Activity 1 - Teaching a NOS-based Lesson}

In the first activity teams of students prepared and taught an explicit NOS based lesson plan. Students selected lessons from among those provided in Chapter 6 "Activities for Teaching about Evolution and the Nature of Science" from Teaching about Evolution and the Nature of Science (National Academy of Sciences 1998). (Note: Each of these published activities is written as a 5-E learning cycle lesson plan.)

\subsubsection{Activity 2 - The Final NOS Continuum}

The second activity asked students to place evolution, intelligent design, and "umbrellaology" (Somerville 1941) along a less-to-more scientific continuum and then to justify in writing their decisions based on accepted criteria. This activity (replicated from our previous action research - see Scharmann et al. 2005) requires students to analyze and synthesize the readings provided during the unit and encourages the consolidation of their personal views of the nature of science in the context of this most difficult task. All fifteen students, four of whom continued to identify themselves as religious conservatives [ 2 are cited case studies below] placed evolution as "most scientific;" thirteen placed "umbrellaology" as intermediate and intelligent design as "least scientific," and two reversed the placement of the latter two fields of study. The unanimity of the placement of evolution as "most scientific" was surprising given that two students (to be discussed below) began the unit by either a flat rejection of evolution or at least a rejection of the "macro" evolutionary theory. We had erroneously assumed that students who reject evolution would not recognize the theory as scientific. This ability of students to recognize evolution as scientific while at the same time rejecting the theory is a crucial finding because such recognition can serve as a prime entry point for instruction with these students. 


\subsubsection{Activity 3 - NOS Quiz Post-administration}

At the close of the NOS unit, student responses ranged from a low of 8 to a high of 12 items correct $(67-100 \%$; mean=79\%). Thus, over the 5 -week span of the NOS unit the lowest student scores doubled from the pretest and the class mean increased by nearly 30\%.

\section{Insights from Selected Case Studies}

Three cases are presented below to illustrate the process of conceptual change that occurred for selected individuals over the course of the NOS instructional unit. All three individuals were students who claimed a very conservative Christian heritage and for whom evolution was not a legitimate scientific theory. [Note: the use of " $\mathrm{T}$ " in the transcripts below refers to teacher comments back to students via electronic mail.]

\subsection{Case 1: Dale}

Dale was raised on a farm in a small midwestern community. She graduated with a major in agricultural education. She has taught high school agriculture for the past three years in a small rural town. Dale enrolled in the Laboratory Techniques class for the purpose of trying to complete a teaching minor in biological sciences so that she can offer agriculture classes for science credit. (Note: In many Midwestern states agricultural courses can substitute for standard science offerings at the secondary school level if the agriculture teacher also is licensed to teach one of the sciences). Dale's first electronic exchange with the instructor began with a carefully couched rejection of evolution:

Dale: "As an instructor and having not taught a unit on evolution, I believe that I would have trouble keeping my personal beliefs out of the classroom regardless of my efforts to do so. However, if I were comparing evolution and creationism by discussing pros and cons of both, my students would be able to form their own opinion or belief one way or the other without any hidden curriculum involved." 
T: "Unfortunately, the issue surrounding an inclusion of creationism or intelligent design in a science classroom is far more complicated. While it may be tempting to include it "out of fairness" to assist students in making up their own minds, doesn't it carry with it the assumption that students will find creationism a compelling argument?"

Dale: "If we present the facts and information in an unbiased manner then we are allowing the students to begin that decision-making process using an experienced-based learning process. What better way for students to learn?"

T: "Might we also need to worry about a different issue - that your approach might cause a student to reject their own religious values because one chooses to include intelligent design?"

Dale: "Probably wouldn't happen. Don't know. I personally believe in creationism, but evolution might fill in some holes."

$\mathrm{T}$ : "I appreciate your honesty in admitting that you believe in creationism yet accept certain aspects of evolution. It has been my intent of twenty plus years to point out the power of scientific theories as problem- solving tools without implying that science has a corner on the market in solving ALL problems." Midway through the NOS unit, Dale takes a different tack in describing how one theory "fills in the holes" of another.

Dale: "As I have stated before, I believe intelligent design or creationism but accept different aspects of evolution. To that I would now add that natural selection does take place and has probably taken place since the beginning of time. This article (Peterson 2002) discusses intelligent design and evolution. Scientifically neither idea is perfect ... both have gaps. I would now agree that intelligent design fills in several holes that the theory of evolution has, but would also argue that evolution does the same for intelligent design. This article was extremely confusing."

T: "I hope that you realize that I am not purposely trying to confuse you."

Dale: "This is not the best article I have read comparing evolution and intelligent design."

$\mathrm{T}$ : "Is it because the article is written by a conservative theological scholar who is openly critical of intelligent design?"

Dale: "No ... it just confuses me more." 
At the close of the NOS instructional unit, Dale cedes some points concerning what makes one scientific theory "more scientific" than another. Although she is still in minor cognitive dissonance, she now places evolution above (if only barely above) intelligent design along the continuum.

Dale: "Since evolution has been studied the theory has changed to some degree and as new information becomes available I am sure that it will change again allowing for self-correction. Skepticism is always a factor in science and especially in evolutionary science. People are extremely skeptical of evolution because it does not agree with what they learned in church and growing up. If evolution is true, then is there a God or higher being? Evolution is more of a scientific theory than intelligent design, however, depending on who you ask it may or may not meet enough of the criteria to be a good scientific theory. I would say it is a science theory, however, it has many limitations."

\subsection{Case 2: Alexis}

Alexis was raised in a small mid-western city to accept a literal interpretation of biblical scripture. She holds a B.S. degree in mathematics education and is currently a Masters degree candidate in Curriculum and Instruction. Instead of teaching in a public school setting after college graduation from undergraduate studies, Alexis chose to work in a private secondary Christian school where she has taught mathematics for the past decade. Alexis was initially hesitant to enroll in the Laboratory Techniques class because of concern that evolution is addressed in the NOS unit.

Alexis: “The AAWOK ['as-a-way-of-knowing'] topic was of particular interest to me because of the distinction between knowing scientifically and knowing religiously. I must admit that the portions concerning evolution were difficult to read. I do believe that God created the heavens and the earth, the earth is not as old as carbon dating or other measures would indicate, and creation is based upon the word of God (omniscient and unfailing) not of man (Darwin). My faith in God supersedes my faith in science in certain areas." 
T: "I had a sense that this section might cause you some difficulty." Alexis: "I guess I got off on a tangent. As a math educator, this article (Smith and Scharmann 1999) was helpful in giving me an overview of what science is and isn't (or more appropriately what is more scientific and less scientific). I see some similarities to the "nature of mathematics" especially in the use of language and wanting students to take their mathematical knowledge to make better, more informed decisions."

$\mathrm{T}$ : "You clearly have little to fear by taking the course and are very secure in your personal faith. My object ... is simply to assist students to see how a theory (such as evolution) is capable of solving problems, making predictions about which we can generate hypotheses, and providing a logical explanation consistent with patterns in present evidence. Science theories do not promote ultimate truths.”

Midway through the NOS unit, Alexis makes a startling discovery (or has a personal epiphany) concerning the difference between proximate (i.e., scientific) and absolute (i.e., theological) truths.

Alexis: "I had never contemplated the difference between truth and scientific truth. This is why I had difficulty grasping the idea of a scientific theory; I thought it was absolute truth. And in the case of evolution, I don't believe it as absolute truth so I couldn't see it as a tool. My thought process was incorrect. This is so hard for me to say because IDT [Intelligent Design Theory] is so appealing to me. Although I have made progress on the whole theory issue, I still need to remind myself that less scientific does not mean worse or wrong thinking."

T: "Right - scientific theories can NEVER be absolute truth. They cease to work in solving problems if they did become absolute truth. And, it is not that your thought processes were incorrect so much as less informed concerning the nature of science."

Alexis: "The line that makes the most sense to me is: "Extraordinary claims require extraordinary evidence." And even though IDT sits well with me, I cannot deny this statement. ID theorists have not produced extraordinary evidence to support their claims."

Finally, at the close of the NOS instructional unit, Alexis now strongly places evolution as more scientific in comparison to 
intelligent design and even considers umbrellaology stronger scientifically than intelligent design. It appears that her "Aha!" recognition of the difference between absolute and proximate causes has had a profound influence on her thinking.

Alexis: "I had minimal experience with NOS thinking - it was very eyeopening. It is still hard for me to separate science, truth, and belief. Intelligent Design (ID), however, is not a science because it is not theologically neutral, values God over physical evidence, and relies on faith. ID is not repeatable, fairly rigid in belief, not openminded, somewhat illogical to believe, and is a "messy" theory. ID meets fewer criterions for being a science than umbrellaology. T: "How does evolution fit in comparison?"

Alexis: "It pains me to say that evolution is a good theory based on the criteria for science. It is empirical, testable, repeatable, fallible, and self-correcting. The theory also possesses large explanatory power, predictability, presents new questions of study, relatively simple to understand, logical, and skeptical (repeatedly tested). I can't believe I just wrote this.”

\subsection{Case 3: Jesse}

Jesse is a traditional undergraduate science education student majoring in chemistry with mathematics as a teaching minor. Jesse, like Dale, was raised in a rural, agriculturally-based community, where being a member of the community equates with strong affiliation with conservative Christian values. Jesse enrolled in the Laboratory Techniques class because it was a required course for graduation/licensure; but, unlike students from similar backgrounds, it was clear from the first day of class that he had looked forward to the course experiences. His e-mails suggest that Jesse was searching for affirmation of personal conceptual change that he had constructed prior to his class enrollment.

Jesse: "I agree that the science teacher should not be an "evangelist," rather the teacher is a facilitator of student understanding and an encourager of student discovery and inquiry. Personally, I was satisfied to both hear from the instructor's mouth and read his words that he is not interested in fostering an environment of persuasion 
or manipulation to a certain point of view. I am pleased that the focus of this class is learning, and I am grateful the instructor practices what he preaches."

T: "Thanks for noticing. Someone who teaches a 'methods of teaching' class has a special obligation to foster instructional models one hopes their graduates will use. So, you found the NOS continuum activities valuable?"

Jesse: "We engaged in fruitful discussions that allowed each of us to voice our reasoning without being divided into camps. As an active participant in the learning exercises, I can honestly say I am convinced that the approach [suggestions for teaching NOS found in Smith \& Scharmann (1999)] is an effective method to help students learn the foundational issues in the NOS while avoiding unproductive arguments over whether an area is or is not a science."

At this point it was clear that Jesse was a careful and thoughtful learner but also that he was withholding his personal NOS positions until he witnessed consistency in the instructor's approach. Although it appears that he wanted to trust the instructor, he did not make his opinions clear until the mid-point of the unit:

Jesse: "I will not hesitate to say that my heart wants IDT to be shown as scientific as evolutionary theory. Moreover, I would like it to be true. Philosophy aside, I recognize that in its current state, IDT provides a weak explanation (at best) as a competing theory for the origin of species and no explanation as a breakthrough theory proving the existence of God. I am comfortable acknowledging that man may never be able to provide a scientific basis for the existence of God. In fact, it even makes sense to me - If God had intended His existence to be shown through hard facts, data, and theory, why would it be necessary to have faith?"

$\mathrm{T}$ : "It appears that you had come to a conclusion on this issue before taking this class. Is that the case?"

Jesse: "I did have some of these thoughts, but didn't have the language to support my ideas. However, as a result of this class, I do now."

$\mathrm{T}$ : "Thus, although you find IDT emotionally compelling, it is logically weak?"

Jesse: "In other words, the payoff of IDT is NOT increased scientific knowledge but rather relief from the attempt to answer 
unanswerable questions. The lack of curiosity about the ID theorists' own theory is remarkable - besides it lacks predictive power of explanation for natural phenomena."

T: "And evolution by comparison?"

Jesse: "Evolution as a theory - the NOS as a whole - appears to be unbiased and objective (even if some of its proponents are not).”

$\mathrm{T}$ : "So you can separate the enterprise of science from the individual scientist?"

Jesse: "The enterprise of science takes no theological position, whereas the individual scientist always has such a choice."

T: "Pretty sophisticated for a 21-year old."

Jesse: “Thanks.”

\section{Further Reflections on Case Studies}

At the beginning of the course Dale, Jesse, and Alexis rejected evolution as a valid scientific theory. At the end of the instructional unit, however, all three accepted the viability of evolutionary theory but with differing levels of emotional response and intellectual understanding. Dale, for example, expressed additional confusion and almost angrily recognized a need to reconsider an issue she thought she had already worked out for herself. In constructing her "less-tomore" scientific diagram for evolution, ID, and Umbrellaology at the end of the instructional unit, she placed evolution only barely above the other two (all three tending toward the middle of the continuum). In contrast, at the end of the unit both Jesse and Alexis placed evolution on the far right (as most scientific), ID on the far left (least scientific) and Umbrellaology squarely in the middle.

Jesse initially stated that he was looking for a means to express his thinking in new ways, while Alexis and Dale were not - the issue of evolution and faith already having been settled both intellectually and emotionally. Yet, while Jesse found additional emotional contentment, Dale reports frustration and Alexis experiences a personal intellectual triumph.

Of the three individuals, Alexis' NOS understanding has clearly come the farthest. She initially told the instructor she didn't even want to take the course because she was afraid her personal beliefs would conflict with the NOS instruction. Post-instruction, however, 
she exhibited a profound clarity in her use of the concepts of proximate and ultimate cause (or "absolute truth" in her words) at the conclusion of the unit. Dale remained uncertain about these concepts. Jesse seems to have found the necessary language he was initially seeking to express a rather sophisticated NOS understanding, much of which be brought into the class.

\section{Summary and Closing Remarks}

This paper presents the philosophical and research underpinnings for an instructional unit on the nature of science that is taught as one of four major themes of a science methods course at a university in a Midwestern state in the U.S. A set of ten tenets that form the unified foundation of the unit is presented. The history of the development of this course over a period of five years has also been presented along with a detailed description of the current structure of the course. The major alteration to earlier iterations has been the inclusion of ostention activities throughout the course. Analysis of both qualitative and limited quantitative data from students in the course has been promising, and this work is presented in the hope that others responsible for designing NOS instruction will find it helpful. The generalizability of our findings is, of course, limited by factors including our limited class sizes, limited use of quantitative research design, and the unique characteristics of our students, but we feel strongly that our methods are likely to be effective in other settings, particularly with students with strong religious/cultural beliefs that oppose informed views of the nature of science.

Experience presenting the course in the past five years has convinced us of the necessity for each of the ten instructional tenets, many of which have been advocated by other researchers (e.g., explicit reflective NOS instruction, using conceptual change and active learning/constructivist methods for teaching NOS, etc.). Two of the primary components of our course design, however, have not been explicitly applied to NOS instruction in any published account: (1) teaching for learning by ostention, and (2) viewing the rejection of naïve NOS views for the adoption of more informed views as a (sometimes impenetrable) cultural border that must be accounted for in instructional design. 
First, we suspect that using ostention activities to promote NOS learning may be wise because students are more experienced, and therefore may be more comfortable and adept, with this method for learning concepts in their everyday world. Second and more importantly, learning by ostention may result in advancing student understanding of the nature of science, as evidenced in the case studies presented here. Like Kuhn's “Johnny" learning from his father to distinguish waterfowl by ostention, our course design makes extensive use of examples. Throughout our course, students are repeatedly presented with pairs of example terms and/or claims and are asked to categorize each term/claim as more or less scientific compared to the other member of the pair, followed by class discussion and consensus building. The pairs are selected so as to be increasingly more conceptually challenging and to involve more significant personal beliefs. This sequencing ensures that students develop standards for judging "more scientific" from "less scientific" and gain expertise in applying those standards before they are asked make judgments likely to be clouded by strongly held personal commitments. In keeping with Kuhn's pedagogical prescriptions and as Schwartz and Bransford (1998) suggest, we find that these activities provide students with the ability to identify for themselves in personally meaningful and fruitful ways the distinctive characteristics of the contrasting classes - in this case, science and non-science. We find that this instructional design provides a scaffolding that is conducive to radical conceptual change about the NOS. In the words of Schwartz and Bransford, learning by ostention provides the learner with "the differentiated knowledge structures necessary to understand a subsequent explanation at a deep level” (p. 504). And “deep learning” about the NOS is our holy grail.

Third, we believe that perhaps too much attention has been focused in the NOS pedagogy literature on the cognitive demands of NOS understanding, and too little attention has been paid to the need for an appreciation that students with radically different views of the nature of science (often concomitant with strongly held conservative religious beliefs) might best be viewed as citizens of radically disparate countries with diametrically opposed worldviews (Cobern 1991). For many of these individuals, merely considering an attempt to understand the basic tenets of theories held by "the other camp" is asking that student to "cross a border" that is greatly feared (Aikenhead and 
Jegede 1999). Persons crossing that border may not only risk the loss of personal identity but may also risk becoming a traitor to oneself and the people they love. This is indeed much to ask of a student who must spend the rest of his life in that world outside the classroom.

Abd-El-Khalick and Akerson (2004) explicitly share our concern for students that harbor conflicting worldviews, but they identify few specific components of their pedagogy aimed to address these concerns and call for others to add their efforts in "the task of translating Aikenhead and Jegede's work “into curricular outcomes and instructional practices" (p. 807). Our NOS unit pays careful attention to "easing border crossings" called for by Aikenhead and Jegede in at least three ways. (1) In every course activity, in all course materials, in every class discussion, and in every e-mail from the instructor, the students' beliefs and personhood are honored and a comfortable, non-confrontational atmosphere is maintained. Students are allowed to hold their own views of the nature of science as long as they have confronted the course readings and learning activities in ways that include examination of their personal NOS views and reasoned justification for those views based on criteria achieved through social consensus building in which they have fully participated. The instructor explicitly tells the students that he will neither attack their values nor demand that they discard their faith and principles. (2) This personally supportive atmosphere encourages Aikenhead and Jegede's (1999) “flexibility and feeling at ease" and Lugones' (1987) "playfulness." In this setting students feel safe to "bend a little." They can "open the door and peek inside" the other world without personal risk. Reflection papers provide a particularly safe avenue for students to "try on" new NOS understandings and see how these ideas fit with the rest of their cognitive, personal, and cultural ecologies and self concepts. The "Umbrellaology" activity especially provides this safe context in which to be "playful" and an opportunity to develop NOS understanding in a non-emotionally laden context. Ensuring that most of the interchanges between the instructor and each student are private and confidential further enhances this student sense of freedom, ease, and flexibility.

Fourth, we believe that students are put at ease, are less defensive, when science is treated as a continuum more than as an absolute dichotomy. In our earlier work (Smith and Scharmann 1999), we proposed that teachers using the continuum approach "should attempt to teach students how to use ... [science] descriptors to judge the relative 
merits of knowledge claims instead of teaching a set of rules that attempt to demarcate science completely from nonscience" (Smith and Scharmann 1999, p. 493). Thus, all of our NOS course materials and activities are carefully selected/designed to demonstrate that the instructor does not hold a black-and-white view of the nature of science, which gives the student the freedom to find his/her own "place to stand" within the continuum of views without being forced to either adopt or reject opposing views en masse.

As Aikenhead and Jegede (1999) also noted, feeling at ease requires in addition

“(a) being a fluent speaker, (b) agreeing with the norms of that culture, (c) being humanly bonded with people in that culture, and (d) having a sense of shared history" (p. 273).

Thus, although the criteria for distinguishing more scientific claims from less scientific claims are generated by the students, the instructor provides them with the standard language used by science educators to describe the consensus characteristics of the NOS (e.g., tentativeness, replicability, fruitfulness, etc.). Skill at using this language is developed throughout the course in settings that carry low risk of embarrassment, including reaction papers with written feedback and private electronic mail exchanges. Thus, the student acquires the tools required to become "a fluent speaker" about the NOS and thus can argue cogently for his/her views in this domain. Likewise, in the person of the instructor, the authors of course readings, and sometimes even other students, students may also become "humanly bonded" with scientists and others who espouse more informed NOS views and thus, through the course of instruction, develop a "sense of shared history" with them. Perhaps even more importantly, learning that many scientists are believers and that many religious leaders do not reject science introduces many students to totally new views of the "norms" of both science and non-science cultures. This new understanding redefines what those norms are, allowing some students for the first time to consider adopting those norms.

Fifth, this study reinforced our appreciation of the necessity for NOS instructors to set an accepting, respectful, and nonjudgmental tone in both formal class activities and private responses to individual students. In previous iterations of the course students such as Dale 
often withdrew entirely from class participation if voicing their opinions created an argument during class, but the current course design makes it unlikely that such negative reactions will occur. Students in this study were more likely to be open to entertaining new NOS understandings in a setting that was non-confrontational, respected their personal beliefs, provided individualized intellectual and emotional scaffolding, and provided them with a temporary place to stand along a continuum instead of a dichotomy of right and wrong. We believe that such a non-threatening climate is essential for enhancing NOS understanding among students for whom more appropriate views of the nature of science represent a cultural border crossing. This approach eases such border crossings because it allows students to advance their NOS understanding more gradually along a continuum. If students such as Dale perceive the learning environment as rejecting their views and as disrespectful of them as persons, their withdrawal may be complete - an opportunity to gain insights into the power and limits of science as a way of knowing lost, potentially forever.

Finally, we concur with the many standards-setting bodies across the globe that have identified understanding the nature of science as a primary goal requisite to effective functioning in the modern world. Achieving informed understandings of the complexities of the nature of science remains a challenging task for students and for in-service and pre-service teachers. Likewise, designing instruction to support NOS learning presents science educators with unique challenges. Although early attempts at NOS instruction met with limited success and early research was sometimes characterized by philosophical disagreements that were tangential to the pedagogical questions, we believe that effective approaches based on a growing consensus in the science education community, including the course described here, are beginning to appear. Refining these instructional methods and determining effective means for promoting their use in both secondary and college settings must be the primary goals for the future.

\section{References}

Abd-El-Khalick, F. \& Akerson, V.L.: 2004, "Learning as Conceptual Change:

Factors Mediating the Development of Pre-Service Elementary Teachers' Views of the Nature of Science," Science Education 88, 785-810. 
Abd-El-Khalick, F. \& Lederman, N.G.: 2000, "Improving Science Teachers' Conceptions of the Nature of Science: A Critical Review of the Literature," International Journal of Science Education 22, 665-701.

Aikenhead, G.S. \& Jegede, O.J.: 1999, "Cross-Cultural Science Education: A Cognitive Explanation of a Cultural Phenomenon," Journal of Research in Science Teaching 36, 269-287.

Akerson, V.L., Abd-El-Khalick, F. \& Lederman, N.G.: 2000, "Influence of a Reflective Explicit Activity-based Approach on Elementary Teachers' Conceptions of Nature of Science," Journal of Research in Science Teaching 37, 295-317.

Alters, B.J.: 1997, "Whose Nature of Science?," Journal of Research in Science Teaching 34, 39-55.

Andersen, H.: 2000, "Learning by Ostention: Thomas Kuhn on Science Education," Science \& Education 9, 91-106.

Bonevac, D.: 1999, Simple Logic, Harcourt, Fort Worth.

Bruner, J., Goodnow, J.J. \& Austin, G.A.: 1967, A Study of Thinking, Science Editions, New York.

Chiappetta, E.L. \& Koballa, T.R.: 2004, "Quizzing Students On the Myths of Science," The Science Teacher 71(9), 58-61.

Clough, M.P. \& Olson, J.K.: 2004, "The Nature of Science: Always Part of the Science Story," The Science Teacher 71(9), 28-31.

Carey, S., Evans, R., Honda, M., Jay, E. \& Unger, C.: 1989, “An Experiment is When You Try It and See if It Works: A Study of Grade 7 Students' Understanding of the Construction of Science Knowledge," International Journal of Science Education 11(5), 514-529.

Carey, S. \& Smith, C.: 1993, "On Understanding the Nature of Scientific Knowledge," Educational Psychologist 28, 235-251.

Cobern, W.W.: 1991, World View Theory and Science Education Research, NARST Monograph $\mathrm{nr}$ 3, National Association for Research in Science Teaching, Columbia, MO, USA.

Dougherty, M.J.: 1997, “Formative Assessment," The Science Teacher 64(6), 29-33.

Driver, R., Leach, J., Millar, R. \& Scott, P.: 1996, Young People's Images of Science, Open University Press, Buckingham, UK.

European Commission: 2001, Europeans, Science and Technology, Eurobarometer 55.2. Available at http://www.europa.eu.int/comm/public"opinion/archives/ eb/ebs"154"en.pdf.

Gilbert, J.K., Osborne, R.J. \& Fensham, P.J.: 1982, "Children's Science and its Consequences for Teaching," Science Education 66, 623-633.

Hewson, P.W., Beeth, M.E. \& Thorley, N.R.: 1998, 'Teaching for Conceptual Change', in K.G. Tobin \& B.J. Fraser (eds.), International Handbook of Science Education, Kluwer Academic Publishers, pp. 199-218.

Joyce, B., Weil, M. \& Calhoun, E.: Models of Teaching, 7th ed., Pearson Education, Inc., Boston, 2004. 
Khishfe, R. \& Abd-El-Khalick, F.: 2002, "Influence of Explicit and Reflective versus Implicit Inquiry-Oriented Instruction on Sixth Graders' Views of Nature of Science," Journal of Research in Science Teaching 39, 551-578.

Kuhn, T.S.: 1962, The Structure of Scientific Revolutions, University of Chicago Press, Chicago.

Kuhn, T.S.: 1970, The Structure of Scientific Revolutions 2nd edn, University of Chicago Press, Chicago.

Kuhn, T.S.: 1974, "Second Thoughts on Paradigms," in F. Suppe (ed.), The Structure of Scientific Theories, University of Illinois Press, Urbana, pp. 459482. Reprinted in T.S. Kuhn, The Essential Tension, University of Chicago Press, Chicago, pp. 293-319.

Kuhn, T.S.: 1979, "Metaphor in Science," in A. Ortony (ed.), Metaphor and Thought, Cambridge University Press, Cambridge, pp. 409-419.

Kuhn, T.S.: 1993, "Afterwords," in P. Horwich (ed.), World Changes. Thomas S. Kuhn and the Nature of Science, MIT Press, Cambridge, MA, pp. 311-341.

Lederman, N.G.: 1992, "Students' and Teachers' Conceptions of the Nature of Science: A Review of the Research," Journal of Research in Science Teaching 29, 771-783.

Lederman, N.G.: 1999, "Teachers' Understanding of the Nature of Science and Classroom Practice: Factors that Facilitate or Impede the Relationship," Journal of Research in Science Teaching 36, 916-929.

Lederman, N. G. \& Abd-El-Khalick, F.: 1998, 'Avoiding De-Natured Science: Activities that Promote Understandings of the Nature of Science', in McComas, W. (ed.), The Nature of Science in Science Education: Rationales and Strategies, Kluwer Academic Publishers, pp. 83-126.

Lugones, M.: 1987, "Playfulness, “World”-Travelling, and Loving Perception," Hypatia 2, 3-19.

McComas, W.F.: 1996, “Ten Myths of Science: Reexamining What We Think We Know about the Nature of Science," School Science and Mathematics 96, 10-15.

McComas, W.F., Clough, M.P. \& Almazroa, H.: 1998, "The Role and Character of the Nature of Science in Science Education," Science and Education 7, 511-532.

National Academy of Sciences: 1998, Teaching about Evolution and the Nature of Science, National Academy Press, Washington.

National Research Council: 1996, National Science Education Standards, National Academy Press, Washington, DC.

National Science Board: 2002, Science and Engineering Indicators-2002, National Science Foundation, Arlington, VA (USA). Also available at http://www.nsf. gov/sbe/srs/seindo $4 /$.

National Science Board: 1996, Science and Engineering Indicators-1996, National Science Foundation, Arlington, VA (USA). Also available at http://www.nsf. gov/statistics/seindg6/.

Nersessian, N.J.: 1998, "Kuhn and the Cognitive Revolution," Configurations 6(1), 87-120. 
Newport, F. \& Strausberg, M.: 2001, 'Americans' Belief in Psychic and Paranormal Phenomena is Up over Last Decade', Gallup News Service (Poll Analyses, 8 June). Available at http://www.gallup.com/poll/releases.

Niaz, M.: 2001, "Understanding the Nature of Science as Progressive Transitions in Heuristic Principles," Science Education 85, 684-69o.

Palmquist, B.C. \& Finley, F.N.: 1997, "Preservice Teachers' Views of the Nature of Science During a Postbaccalaureate Science Teaching Program," Journal of Research in Science Teaching 34, 595-615.

Peterson, G.R.: 2002, “The Intelligent-Design Movement: Science or Ideology?," Zygon 37(1), 7-23.

Rosch, E.: 1978, "Wittgenstein and Categorization Research in Cognitive Psychology," in M. Chapman and R.A. Dixon (eds.), Meaning and the Growth of Understanding. Wittgenstein's Significance for Developmental Psychology, Springer, Berlin, pp. 151-166.

Scharmann, L.C. \& Smith, M.U.: 2001, "Further Thoughts on Defining versus Describing the Nature of Science: A Response to Niaz," Science Education 85, 691-693.

Scharmann, L.C., Smith, M.U., James, M.C. \& Jensen, M.: 2005, "Explicit Reflective Nature of Science Instruction: Evolution, Intelligent Design, and Umbrellaology," Journal of Science Teacher Education 16, 27-41.

Schwartz, D.L. \& Bransford, J.D.: 1998, “A Time for Telling," Cognition and Instruction 16, 475-522.

Scott, E.C.: 1999, "The Creation/Evolution Continuum," Reports of the National Center for Science Education 19(4), 16-23.

Smith, M.U., Lederman, N.G., Bell, R.L., McComas, W.F. \& Clough, M.P.: 1997, "How Great is the Disagreement about the Nature of Science? A Response to Alters," Journal of Research in Science Teaching 34, 1101-1103.

Smith, C.L., Maclin, D., Houghton, C. \& Hennessey, M.G.: 200o, “'Sixth-Grade Students' Epistemologies of Science: The Impact of School Science Experiences on Epistemological Development," Cognition and Instruction 18, 349-422.

Smith, E.E. \& Medlin, D.L.: 1981, Categories and Concepts, Harvard University Press, Cambridge.

Smith, M.U. \& Scharmann, L.C.: 1999, "Defining versus Describing the Nature of Science: A Pragmatic Analysis for Classroom Teachers and Science Educators," Science Education 83, 493-509.

Somerville, J.: 1941, "Umbrellaology or Methodology in Social Science," Philosophy of Science 8, 557-566. 